Int. J. Electrochem. Sci., 16 (2021) Article ID: 210215

International Journal of

ELECTROCHEMICAL

SCIENCE

www.electrochemsci.org

\title{
Analysis of transient characteristics for zinc-nickel single flow battery considering side reactions
}

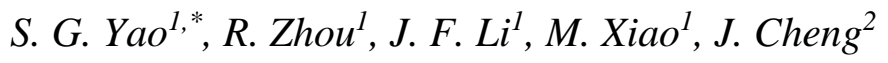 \\ ${ }^{1}$ Jiangsu University of Science and Technology, 212003, Zhenjiang, Jiangsu, China \\ ${ }^{2}$ Zhejiang Yuyuan Energy Storage Technology Co., Ltd., 313100, Huzhou, Zhejiang, China \\ *E-mail: zjyaosg@126.com
}

doi: $10.20964 / 2021.02 .15$

Received: 3 Ocober 2020 / Accepted: 23 November 2020 / Published: 31 December 2020

\begin{abstract}
A two-dimensional transient model of zinc-nickel single flow battery considering side reaction is developed and is used to study the effects of concentration, flow rate and applied current density on the side reaction. The results indicate that the generation of oxygen in the positive electrode is mainly at the end of charging, the generation of hydrogen in the negative electrode starts at the beginning of charging. As time goes on, the hydrogen evolution side reaction gradually weakens. The amount of hydrogen produced during charging is much less than that of oxygen. Decreasing the initial hydroxide ions concentration within a certain range can effectively inhibit the oxygen evolution side reaction, but it will aggravate the hydrogen evolution side reaction. Reducing the initial concentration of zincate ions has little effect on the oxygen evolution side reaction, but it will aggravate the hydrogen evolution side reaction. The effect of zincate ions on hydrogen evolution reaction is much smaller than that of hydroxide ions. The increase of the electrolyte flow rate reduces concentration polarization and has inhibitory effect on the side reaction of the battery electrode. Increasing the applied current density within a certain range will aggravate the side reaction of the battery electrode.
\end{abstract}

Keywords: zinc-nickel single flow battery, side reaction, concentration, flow rate, applied current density.

\section{$\underline{\text { FULL TEXT }}$}

(C) 2021 The Authors. Published by ESG (www.electrochemsci.org). This article is an open access article distributed under the terms and conditions of the Creative Commons Attribution license (http://creativecommons.org/licenses/by/4.0/). 